\title{
Changes in Skeletal Muscle and Body Weight on Sleeping Beauty Transposon-Mediated Transgenic Mice Overexpressing Pig mIGF-1
}

\author{
Bo Gao ${ }^{1} \cdot$ Wei Wang ${ }^{1} \cdot$ Han Wu ${ }^{1} \cdot$ Cai Chen ${ }^{1} \cdot$ Dan Shen $^{1} \cdot$ Saisai Wang ${ }^{1}$. \\ Wei Chen ${ }^{1} \cdot$ Li Zhang $^{1} \cdot$ Shuheng Chan ${ }^{1} \cdot$ Chengyi Song ${ }^{1}$
}

Received: 16 October 2017 / Accepted: 10 February 2018 / Published online: 22 February 2018 (C) The Author(s) 2018. This article is an open access publication

\begin{abstract}
Insulin-like growth factor (IGF-I) is an important growth factor in mammals, but the functions of the local muscle-specific isoform of insulin-like growth factor 1 (mIGF-1) to skeletal muscle development have rarely been reported. To determine the effect of pig mIGF-1 on body development and muscle deposition in vivo and to investigate the molecular mechanisms, the transgenic mouse model was generated which can also provide experimental data for making transgenic pigs with pig endogenous IGF1 gene. We constructed a skeletal muscle-specific expression vector using 5'- and 3'-regulatory regions of porcine skeletal $\alpha$-actin gene. The expression cassette was flanked with Sleeping Beauty transposon (SB)-inverted terminal repeats. The recombinant vector could strongly drive enhanced green fluorescence protein (EGFP) reporter gene expression specifically in mouse myoblast cells and porcine fetal fibroblast cells, but not in porcine kidney cells. The EGFP level driven by $\alpha$-actin regulators was significantly stronger than that driven by cytomegalovirus promoters. These results indicated that the cloned $\alpha$-actin regulators could effectively drive specific expression of foreign genes in myoblasts, and the skeletal muscle-specific expression vector mediated with SB transposon was successfully constructed. To validate the effect of pig mIGF-1 on skeletal muscle growth, transgenic mice were generated by pronuclear microinjection of SB-mediated mIGF-1 skeletal expression vector and SB transposase-expressing plasmid. The transgenepositive rates of founder mice and the next-generation F1 mice were 30\% (54/180) and $90.1 \%$ (64/71), respectively. The mIGF-1 gene could be expressed in skeletal muscle specifically. The levels of mRNA and protein in transgenic mice were 15 and 3.5 times higher, respectively, than in wild-type mice. The body weights of F1 transgenic mice were significantly heavier than wild-type mice from the age of 8 weeks
\end{abstract}

Chengyi Song

cysong@yzu.edu.cn

1 Joint International Research Laboratory of Agriculture and Agri-product Safety, College of Animal Science \& Technology, Yangzhou University, Yangzhou 225009, China 
onwards. The paraffin-embedded sections of gastrocnemius from 16-week-old transgenic male mice showed that the numbers of myofibers per unit were increased in comparison with those in the wild-type mice. mIGF-1 overexpression in mice skeletal muscle may promote myofibers hypertrophy and muscle production, and increased the average body weight of adult mice. Transgenic mice models can be generated by the mediation of SB transposon with high transgene efficiency.

Keywords Pig insulin-like growth factor $1 \cdot$ Transgenic mice $\cdot$ Skeletal $\alpha$-actin gene regulator $\cdot$ Sleeping Beauty transposon

\section{Introduction}

Insulin-like growth factor 1 (IGF-1) plays a fundamental role in cell proliferation and differentiation, and regulates postnatal mammalian growth and development (Tonkin et al. 2015). The primary structure of IGF-1 is highly conserved in placental mammalian species. Canine, bovine, ovine, porcine, and human IGF-1 s are identical, whereas rat and mouse IGF-1s differ from human IGF-1 by 3 and 4 amino acids, respectively (Shavlakadze et al. 2005). The IGF-1 gene is a single copy and is highly conserved in structure in mammals, containing six exons and five introns. The heterogeneity of IGF-1 transcripts is complicated because of the use of alternative transcription start sites (Yang et al. 1995), alternative posttranscriptional exon splicing (Bell et al. 1986), and the use of different polyadenylation sites (Lund et al. 1989). IGF-1 mRNA was expressed in different tissues at different abundance. The predominant IGF-1 mRNA variant expressed in skeletal muscle (Sk muscle) is initiated at exon 1 (Class 1, C1) and represents an exon 4-6 spliced variant, which encodes an IGF-1 isoform containing an Ea peptide (Musaro et al. 2001), which is also referred to as a "local muscle-specific" isoform of IGF-1 (mIGF-1). Overexpression of human or mouse mIGF-1 can significantly promote muscle growth of transgenic (Tg) mice (Coleman et al. 1995; Musaro et al. 2001). mIGF-1 can promote myoblast proliferation and fusion of myofibers, which can result in muscle hypertrophy (Coleman et al. 1995). mIGF-1 knock-out mice showed slow growth and immature or early death, with serious defects in muscle development (Shavlakadze et al. 2005).

The effects of promoters on transgene expression are important. Coleman et al. (1995) utilized the metallothionein promoter to drive expression of human mIGF-1 cDNA in Tg mice, resulting in IGF-1 overexpression in a broad range of visceral internal organs and increased concentrations of IGF-1 in serum. These Tg mice exhibited an increase in body weight and organomegaly, but only a modest improvement in muscle mass. To test the effects of mIGF-1 overexpression on Sk muscle growth and physiology, it would be necessary to target its overexpression specifically in Sk muscle. At present, two promoters of skeletal $\alpha$-actin (Asante et al. 1994) and myosin light chain (MLC1/3) (Rosenthal et al. 1989) are often used, which are active in differentiated skeletal or cardiac muscle cells. Skeletal $\alpha$-actin is the major actin isoform in adult Sk muscle (Gunning et al. 1987; Asante et al. 1994), which suggests that the promoter for skeletal $\alpha$-actin is strong. The contiguous 
3'-untranslated region (UTR) of the skeletal $\alpha$-actin gene can directly correct the temporal and spatial expression of skeletal actin-based transgenes in mice (Brennan and Hardeman 1993).

The Sleeping Beauty (SB) transposon system is extremely effective at delivering DNA to vertebrate genomes (Ivics et al. 2004). The system consists of two parts: a transposon and a source of transposase. The transposon vector consists of inverted terminal repeats (ITRs) that flank an expression cassette. The transposon can be mobilized when SB transposase is supplied in transgene. Transposase binds at precise sites in each of the ITRs where it cuts out the transposon and inserts it into a new DNA locus (Geurts et al. 2003). SB-mediated transgene delivery is well developed in fish, mammals (mouse, rabbit, and pig), frogs, and poultry (Carlson et al. 2011a; Mátés 2011; Ivics et al. 2014; Tschida et al. 2014). As an efficient transgene delivery tool, the SB transposon system has four attractive features: low immunoreactivity, easy uptake of transposons into cell nuclei by the nuclear localization signal of SB transposase (Zanta et al. 1999), large carrying capacity of the transposon for efficient integration into chromosomes, and long-term expression stability of transposed genes even following passage through the germ-line (Luo et al. 1998; Yant et al. 2000; Fischer et al. 2001; Horie et al. 2001; Carlson et al. 2011b).

In this report, a myogenic expression vector containing regulatory elements from both the 5'- and 3'-flanking regions of the pig skeletal $\alpha$-actin gene was constructed, and a transgenic mouse model expressing pig mIGF-1 specifically in Sk muscle was generated. To increase the transgene efficiency, the SB transposon was used to mediate the myogenic expression vector. This paper studied the effect of pmIGF-1 overexpression in Sk muscle on $\mathrm{Tg}$ mice growth and the proliferation and differentiation of myoblasts, and provides an effective method for generating transgenic pigs.

\section{Materials and Methods}

\section{Construction and Characterization of Skeletal Muscle-Specific Expression Vector}

SB transposon-mediated vectors were constructed using the standard molecular cloning techniques. To construct skeletal-specific expression vectors, pig skeletal $\alpha$-actin gene regulators including the $5^{\prime}$ core promoter, upstream activating sequences, natural cap site, 5'-UTR (exon 1), first intron, and portions of exon 2 up to the initiation ATG sequence. 3'-UTR and contiguous 3'-noncoding regions were amplified from pig genome DNA by high-fidelity polymerase chain reaction (PCR) using primers designed according to sequences published previously (Table 1). The PCR products were cloned into pGEM-T vectors and confirmed by sequence analysis. The 5'- and 3'-regulatory regions were then subcloned into the pGL3-control vector and the resulting vector was named pGL3-2. mIGF-1 cDNA was cloned from pig liver total RNA by reverse-transcription PCR using primers designed according to sequences published previously (Table 1). After sequencing, the mIGF-1 cDNA was subcloned downstream of the 5'-regulatory region of pGL3-2 into the EcoRI and NcoI restriction enzyme sites, and the resulting vector was named pA-actin-mIGF-1. 
Table 1 Primer sequences for vector construction

\begin{tabular}{|c|c|c|}
\hline & Sequences $\left(5^{\prime} \rightarrow 3^{\prime}\right)$ & Product (bp) \\
\hline \multirow[t]{2}{*}{$\alpha$-actin-5 } & F: cgGGTACCGATATCcagcagaaattgacggaaca & 2512 \\
\hline & R: aaACGCGTatGAATTCggcgtcgggtttctgcaa & \\
\hline \multirow[t]{2}{*}{$\alpha$-actin-3 } & F: aat $C C A T G G$ acccattccaacagctg & 751 \\
\hline & R: agGTTAACtaGCGGCCGCatcaacacccggcttgaa & \\
\hline \multirow[t]{2}{*}{ SV40 enhancer } & $\mathrm{F}:$ at $G C G G C C G C$ tgaacgatggagcggaga & 242 \\
\hline & R: gcGTTAACGATATC cgctgtggaatgtgtgtca & \\
\hline \multirow[t]{2}{*}{ mIGF-1 } & F: gcGAATTCttgcacttcagaagcaatgg & 478 \\
\hline & $\mathrm{R}:$ gcCCATGGctacattctgtagttcttgtttcc & \\
\hline \multirow[t]{2}{*}{ eGFP } & F: atGAATTCatggtgagcaagggcgagga & 720 \\
\hline & R: agCCATGGttacttgtacagctcgtcca & \\
\hline
\end{tabular}

Then, the mIGF-1 expression cassette was cut from pA-actin-mIGF-1 with EcoRV and subcloned into EcoRV sites in the SB transposon vector pT2-HB (provided by Dr. Moore, University of Minnesota). The resulting vector was named pT2/A-actinmIGF-1 (Fig. 1).

To evaluate whether the vector could specifically drive expression of the gene of interest in skeletal cells, IGF-1 was replaced by the enhanced green fluorescence protein (EGFP) reporter gene and the recombinant vector pT2/A-actin-EGFP (Fig. 1) was transfected into mouse myoblast cells (C2C12; ATCC CRL-1772), porcine fetal fibroblast cells (PEF; primary culture), and porcine kidney cells (PK15; ATCC CCL-33). One day before transfection, $2 \times 10^{5}$ cells per well were plated in a 24-well plate. When the cells were $90-95 \%$ confluent, $0.8 \mu \mathrm{g}$ DNA packed with $2 \mu \mathrm{L}$ Lipofectamine 2000 was added according to the manufacturer's instructions (Invitrogen, Carlsbad, CA, USA) to each well. The cells were incubated at $37{ }^{\circ} \mathrm{C}$ in a $\mathrm{CO}_{2}$ incubator for $24 \mathrm{~h}$ prior to testing for transgene expression. For each cell type, three treatment groups [pT2/A-actin-EGFP, pEGFP-N1, and blank (Lipofectamine 2000 only)] were tested, with each group tested in triplicate.

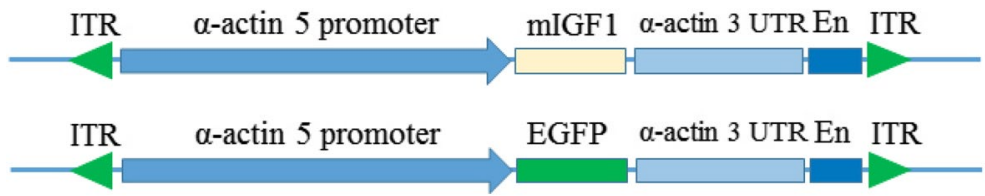

Fig. 1 Schematic diagram of skeletal-specific expression vector mediated by Sleeping Beauty (SB) transposon. ITR: inverted terminal repeat of SB; $\alpha$-actin 5 promoter: 5'-regulator for skeletal $\alpha$-actin gene; mIGF-1: mIGF-1 open reading frame; $\alpha$-actin 3 UTR: 3 '-untranslated region and contiguous $3^{\prime}$-noncoding region for skeletal $\alpha$-actin gene; En: SV40 enhancer 


\section{Generation, Detection, and Breeding of Transgenic Mice}

The SB transposon plasmid pT2/A-actin-mIGF-1 and transposase-encoding plasmid pCMV-SB11 (provided by Dr. Moore, University of Minnesota) were prepared using an EndoFree plasmid maxi preparation kit (Qiagen, German). Transposon DNA and transposase DNA were mixed at the mass ratio of 2:1 and microinjected into the cytoplasm of C57BL/J6 mice fertilized eggs. $\mathrm{G}_{0}$ founder mice were tested for transgene integration using PCR and Southern blot analysis. Mouse tail DNA was isolated and subjected to PCR using specific primers (Table 2). The length of target products was $545 \mathrm{bp}$. Southern blot analysis was used to identify PCR-positive founder mice. Tail genomic DNA was digested with the restriction enzyme EcoRV, separated on a $0.8 \%(\mathrm{w} / \mathrm{v})$ agarose gel, and transferred to positively charged nylon membranes (Roche). The blots were hybridized with 311 bp DIG-labeled probes prepared with the PCR DIG probe synthesis kit (Roche) using the primers designed according to the sequence of mIGF-1 cDNA (Table 2). The fragment of pT2/A-actin-mIGF-1 plasmid DNA digested with EcoRV was used as a positive control. The transgenic mouse experiments were carried out in the Institute of Zoology, Chinese Academy of Sciences. The three male founders were mated with wildtype $(\mathrm{Wt})$ female mice at the ratio of 1:4 to generate three transgenic lines. Wt mice lines were used as the control.

\section{Transcriptional Profiling of Pig mIGF-1 by Real-Time Quantitative PCR Assays}

The total RNA of fresh tissues from transgenic and normal mice, including Sk muscle, heart, liver, lung, kidney, testis, and seminal vesicle, were isolated using TRIzol Reagent (Invitrogen). The first-strand cDNA was synthesized with $2 \mu \mathrm{g}$ total RNA as template using RevertAid ${ }^{\mathrm{TM}}$ First-Strand cDNA Synthesis Kit (Thermo). The mIGF-1 expression level in each tissue was detected by qPCR (Applied Biosystems 7500 Real-Time PCR System) using SYBR Premix Ex Taq (Takara). Each assay was conducted with three tissue samples and the qPCR reactions for each sample were set up in triplicate. Endogenous mouse $\beta$-actin gene was used as an internal control. The specific primers are listed in Table 3. Identical amplification reaction conditions

Table 2 Primers for screening transgenic mice

\begin{tabular}{lll}
\hline & Primer sequences $\left(5^{\prime} \rightarrow 3^{\prime}\right)$ & Product $(\mathrm{bp})$ \\
\hline P1 $(\alpha$-actin 5') & $\begin{array}{l}\text { F: ccaggttgctcggattgat } \\
\text { R: attgggttggaagactgctg }\end{array}$ & 206 \\
P2 ( $\alpha$-actin 3') & $\begin{array}{l}\text { F: atcgtggatgagtgctgctt } \\
\text { R: cacttgagcagattcgtcgt }\end{array}$ & 251 \\
P3 (pmIGF-1 cDNA) & $\begin{array}{l}\text { F: gccttgctgatcttgcagaa } \\
\text { R: gaagtcgcagctgttggaat }\end{array}$ & 545 \\
& F: cagcagtcttccaacccaat \\
Probe primer & R: acatctccagcctcctcaga & \\
\end{tabular}


Table 3 Primers for real-time quantitative PCR

\begin{tabular}{lll}
\hline & Primer sequences $\left(5^{\prime} \rightarrow 3^{\prime}\right)$ & Product $(\mathrm{bp})$ \\
\hline IGF-1 & F: TTATTTCAACAAGCCCACA & 111 \\
& R:TACATCTCCAGCCTCCTCA & \\
$\beta$-actin & F: CTCTTTTCCAGCCTTCCTT & 112 \\
& R: GTGTTGGCATAGAGGTCTT & \\
\hline
\end{tabular}

consisting of DNA denaturation at $95{ }^{\circ} \mathrm{C}$ for $30 \mathrm{~s}, 40$ cycles each of the denaturation step at $95^{\circ} \mathrm{C}$ for $5 \mathrm{~s}$, and an annealing/extension step at $60^{\circ} \mathrm{C}$ for $34 \mathrm{~s}$ were used for each gene analyzed. A final dissociation stage consisted of $95{ }^{\circ} \mathrm{C}$ for $15 \mathrm{~s}, 60{ }^{\circ} \mathrm{C}$ for $1 \mathrm{~min}$, and $95^{\circ} \mathrm{C}$ for $15 \mathrm{~s}$. The reaction volume was kept at $20 \mu \mathrm{L}$ by including $1 \mu \mathrm{L}$ cDNA. The relative abundance of transcripts of each gene was calculated according to the comparative $2^{-\Delta \Delta C T}$ method (Schefe et al. 2006).

\section{Translational Profiling of Pig mIGF-1 by Western Blot}

To prepare proteins from tissue samples, $\sim 100 \mathrm{mg}$ of fresh or frozen $\left(-80{ }^{\circ} \mathrm{C}\right)$ tissue samples were placed in an Eppendorf tube. Approximately $1 \mathrm{~mL}$ of ice-cold lysis buffer was rapidly added to the tube. The tissue was homogenized with an electric homogenizer, vortexed, and mixed well several times, and then centrifuged for $10 \mathrm{~min}$ at $12,000 \mathrm{rpm}, 4{ }^{\circ} \mathrm{C}$. The concentration of the protein in the supernatant was tested. Samples $(40 \mu \mathrm{g})$ of total denatured protein from the tissue homogenate were boiled with $1 \times$ loading buffer at $100{ }^{\circ} \mathrm{C}$ for $5 \mathrm{~min}$ and loaded into the wells of a $20 \%$ SDS-PAGE gel for separation. Proteins were transferred from the gel to a PVDF membrane (Millipore). The membrane was incubated with rabbit anti-human IGF-1 antibody at 1:200 dilution (Abcam) and goat anti-Rabbit IgG H\&L (HRP) secondary antibody at 1:5000 dilution (Abcam). The signal was developed with the chemiluminescent HRP substrate ECL (Amersham), and images were acquired using darkroom development techniques for chemiluminescence. Mouse $\beta$-actin was used as an internal control.

\section{Phenotypic Analysis of Transgenic mice}

The body weight of male or female Tg mice or normal mice was detected from 3 to 16 weeks of age. Growth curves based on body weight were used to compare the growth rate between transgenic and normal mice. Hind leg gastrocnemius obtained from 16-week-old male mice were fixed in 4\% PFA for $24 \mathrm{~h}$ at room temperature, dehydrated with ethanol, and embedded in paraffin. Histopathologic evaluation was performed on deparaffinized sections stained by routine hematoxylin and eosin (H\&E) staining. 


\section{Statistical Analyses}

Unpaired $t$ tests were used for comparisons between age-matched control and pmIGF-1 Tg mice. Statistical significance was accepted for comparisons where $P<0.05$.

\section{Results}

\section{Characterization of the Transgene Construct in Tissue Culture}

To validate the $\mathrm{Sk}$ muscle-specific expression vector, pT2/A-actin-EGFP was transfected into $\mathrm{C} 2 \mathrm{C} 12$, PEF, and PK15 cells. After $24 \mathrm{~h}$ of transfection, green fluorescence could be tested under the fluorescence microscope. The results showed that EGFP was expressed in C2C12 and PEF cells, but not in PK15. The GFP fluorescence signals in $\mathrm{C} 2 \mathrm{C} 12$ were significantly stronger than those in PEF, which suggested that the expression level of pT2/A-actin-EGFP in C2C12 was significantly higher than that of pEGFP-N1 (Fig. 2). These results suggested that the constructed vector was suitable for Sk muscle-specific expression, and that the 5'- and 3 '-regulatory regions of $\alpha$-actin were more favorable for effectively expressing exogenous genes than cytomegalovirus promoters in Sk muscle.

\section{Generation of Pig mIGF-1 Transgenic Mice}

The pig mIGF-1 Sk muscle-specific expression cassette harbored by the SB transposon and SB transposase expression plasmid were co-microinjected into the male pronucleus of zygotes from the C57BL/J6 mice, which led to 180 live births. Based on the PCR and Southern blot analyses of tail DNA (Fig. 3), 54 founders were identified to be transgenic. The transgene efficiency was 30\%, which was higher than that for common plasmid vectors $(0.5-5 \%)$ (Tesson et al. 2005). There were three male mice (1\#, 2\# and 9\#) among the 54 founders. The three male founders generated three transgenic lines by mating with $\mathrm{Wt}$ mice. The average positive rate of F1 was about $90.1 \%$ (Table 4).

\section{pmIGF-1 Expression Level in Tissues of Transgenic Mice}

To validate the tissue distribution of pmIGF-1 expression, total RNA extracted from seven tissues (Sk muscle, heart, liver, lung, kidney, testis, and Se vesicle) of F1 Tg and Wt mice was analyzed by qRT-PCR. pmIGF-1 was expressed in Sk muscle, heart, liver, and testis of both $\mathrm{Tg}^{+}$and Wt mice. Among the tissues tested, the expression level in Sk muscle was the highest. The expression in Sk muscle of $\mathrm{Tg}$ mice was 15 times higher than that in Sk muscle of Wt mice. The expression in heart or liver was not significantly different between Tg and Wt mice. Although the expression level in testes of Tg mice was much higher than that in testis of Wt mice, the expression levels were generally very low in testis (Fig. 4a). The seven tissue 

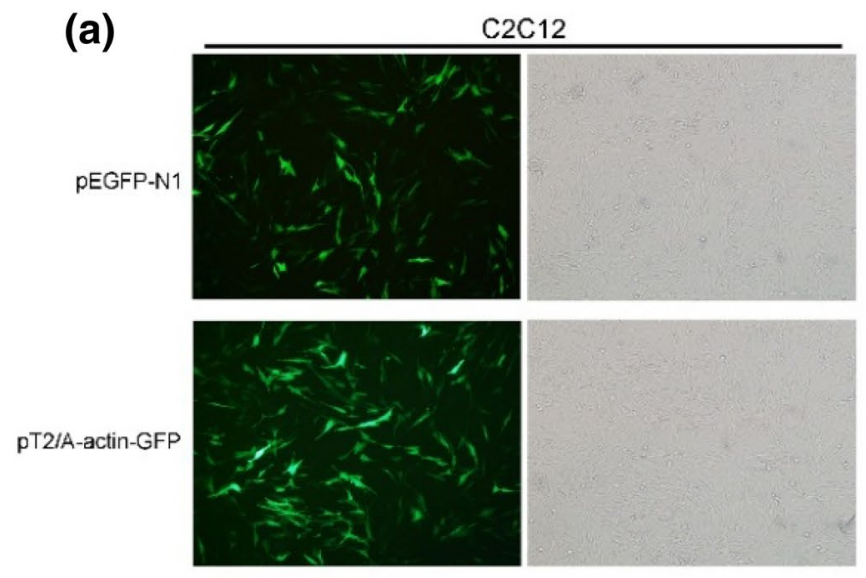

(b)
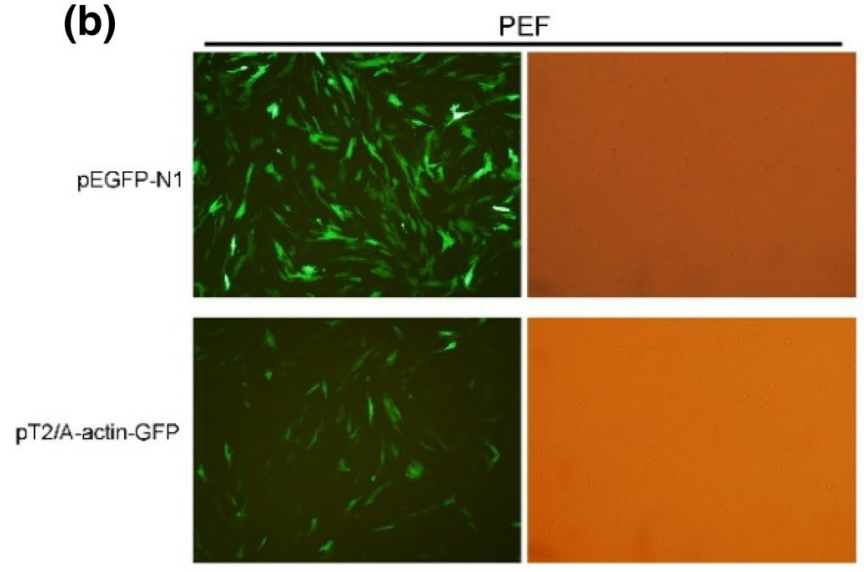

(c)

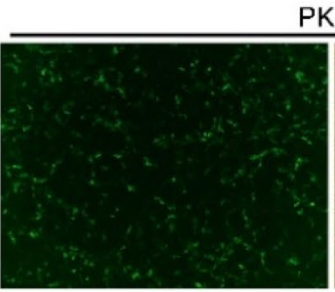

PK15

pEGFP-N1

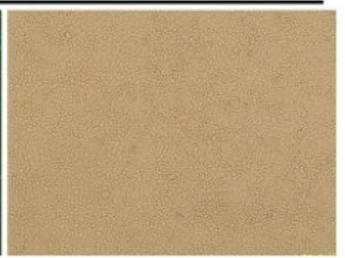

pT2/A-actin-GFP
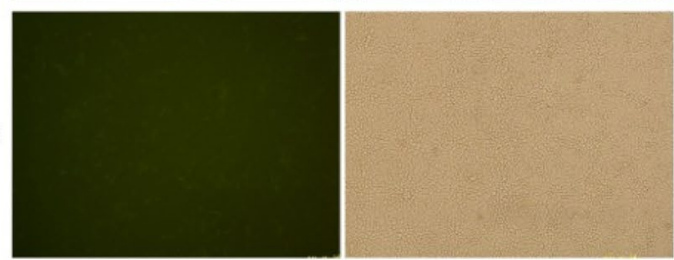

Fig. 2 Green fluorescent protein expression in different cell types. The vector pT2/A-actin-EGFP was transfected into a mouse myoblast $(\mathrm{C} 2 \mathrm{C} 12)$, b porcine fetal fibroblast $(\mathrm{PEF})$, and $\mathbf{c}$ porcine kidney (PK15) cells. pEGFP-N1 was used as a positive control 
(a)
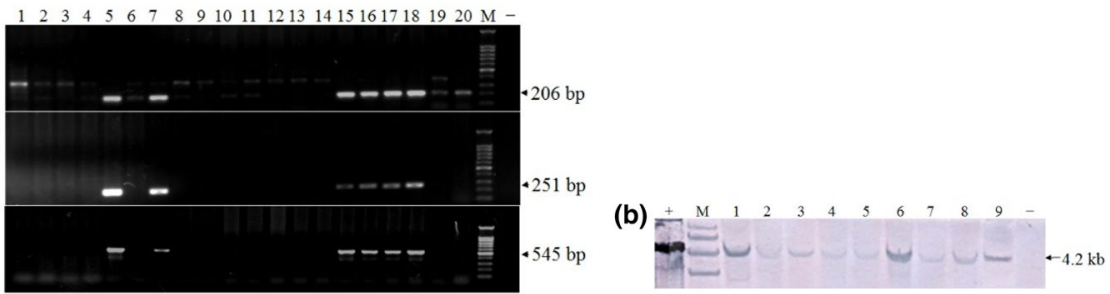

Fig. $3 \mathrm{~F}_{0}$ founder mice were tested for transgene integration. a Mouse tail genomic DNA was subjected to PCR using three pairs of specific primers designed according to transgene sequences: $\alpha$-actin- $5^{\prime}$ (206 bp), $\alpha$-actin-3' (251 bp), pIGF-1-flank (545 bp). 1-20, F founders; M, 100 bp DNA ladder; -, Wt mouse; b PCR-positive individuals were tested by Southern blot analysis. Mouse tail genomic DNA was digested with EcoRV and hybridized with DIG-labeled probes. +, pT2/A-actin-IGF-1/EcoRV; M, DNA molecular weight marker III labeled with Digoxigenin; 1-9, PCR-positive $\mathrm{F}_{0}$ founders, -, Wt mouse

Table 4 Summary results for transgenic mouse lines

\begin{tabular}{llll}
\hline $\begin{array}{l}\text { Founder } \begin{array}{l}\text { X wild- } \\
\text { type C57BL/J6 }\end{array} \\
\text { Line 1\# }\end{array}$ & $\begin{array}{l}\text { Total no. of } \\
\text { pups }\end{array}$ & $\begin{array}{l}\text { No. of IGF-1 } \\
\text { pups }\end{array}$ & $\begin{array}{l}\text { Percentage of } \\
\text { IGF-1 }^{+} \text {pups }\end{array}$ \\
\hline Line 2\# & 23 & 21 & 91.3 \\
Line 9\# & 23 & 20 & 87.0 \\
Total & 25 & 23 & 92.0 \\
\hline
\end{tabular}

(a)

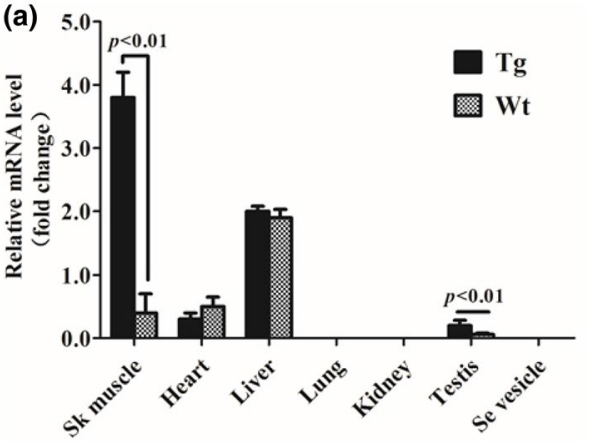

(b)

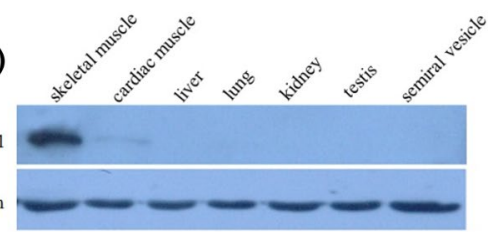

Fig. 4 IGF-1 gene expression in transgenic mouse tissues. a IGF-1 mRNA expression levels determined by real-time quantitative PCR; b IGF-1 protein levels determined by Western blot analysis

lysates of $\mathrm{Tg}$ mice were analyzed by Western blotting using a polyclonal human IGF-1 antibody with aa sequences the same as those of pmIGF-1 antibody, and four aa difference with mouse IGF-1 antibody. Among the analyzed tissues, pmIGF-1 could only be detected in Sk muscle and heart, and the expression level in Sk muscle was much higher than that in heart. The human mIGF-1 antibody specifically recognized Sk muscle IGF-1 with little or no cross-reactivity to other tissues (Fig. 4b). 
Fig. 5 IGF-1 levels of gastrocnemius from Wt and pmIGF-1 Tg mice by Western blotting
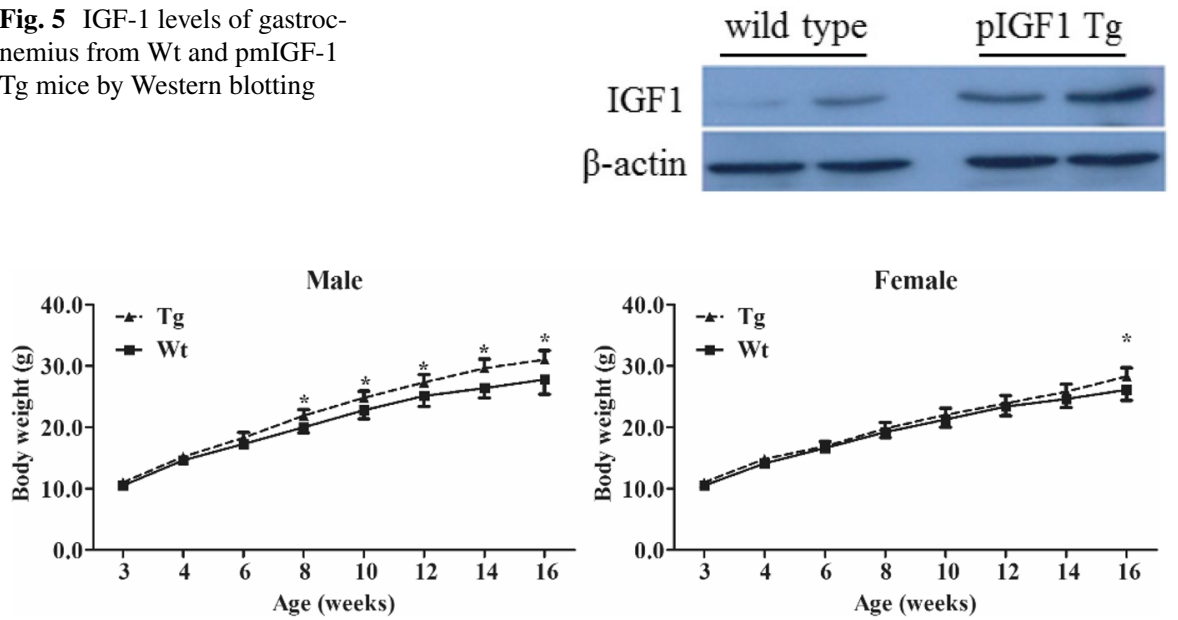

Fig. 6 Growth curves of transgenic mice. $T g$ transgenic mice, $W t$ wild-type mice. ${ }^{*} P<0.05$ (determined using the Student's $t$ test, comparing Wt and Tg mice)

These results suggested that pmIGF-1 was specifically expressed in Sk muscle of Tg mice.

The pmIGF-1 expression levels of Sk muscle from Tg mice were compared with those of Wt mice by the signal intensity on the Western blot determined by image analysis. The IGF-1 expression level in Tg mouse leg gastrocnemius was 3.5 times higher than that in Wt mice (Fig. 5).

\section{Growth Curve of $\mathrm{Tg}^{+}$Mice}

The body weights of F1 $\mathrm{Tg}$ mice were determined from 3 to 16 weeks of age (Fig. 6). The body weight of male Tg mice was significantly heavier than that of Wt mice from 8 weeks old, and that of female Tg mice became heavier than that of Wt mice from 16 weeks of age (Fig. 6). These data suggested that exogenous IGF-1 expressed in Sk muscle facilitated the muscle growth of Tg mice at adult stage, and male mouse growth was affected at an earlier developmental stage than female.

\section{Skeletal Muscle Histology}

To investigate the changes in muscle tissues, paraffin-embedded sections of 16-week-old mouse gastrocnemius were analyzed by H\&E dye. The per unit numbers of myofibers from Tg mice were increased when compared with age-matched controls. The pmIGF-1 overexpression promoted myofiber proliferation and muscle hypertrophy (Fig. 7). 

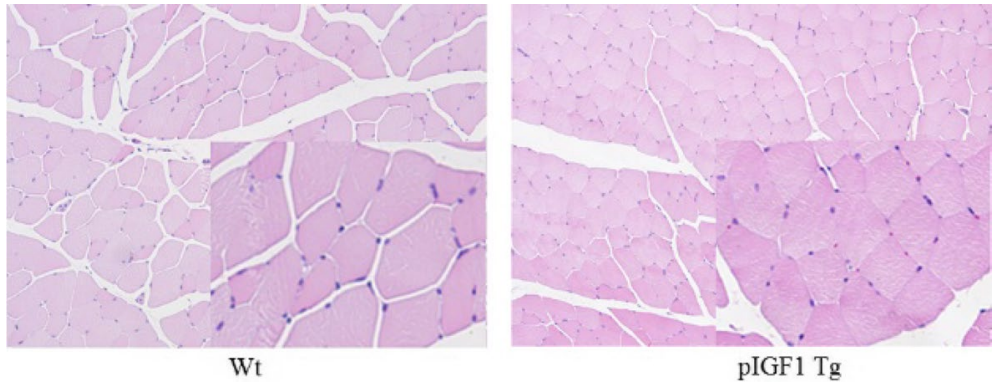

Fig. 7 Hematoxylin and eosin histology of 16-week-old $\mathrm{Tg}$ and $\mathrm{Wt}$ mouse gastrocnemius. Images revealed the fiber hypertrophy in pmIGF-1 Tg. The magnification was $\times 100$ and $\times 400$ (inset)

\section{Discussion}

Alternative splicing of IGF-1 transcripts results in complexity of IGF-1 isoforms. The predominant isoform in Sk muscle is Class 1 (initiated at exon 1) IGF-1 Ea (Ea peptide from an exon 4-6 spliced variant). mRNA encoding the Class 1 IGF-1 Ea isoform is expressed locally in muscle (Musaro et al. 2001). To study the function of IGF-1 Ea, Tg mice expressing human mIGF-1 Ea or mIGF-1 Ea specifically in Sk muscle were developed. The overexpression of IGF-1 Ea can promote myofiber proliferation or heart hypertrophy (Coleman et al. 1995; Musaro et al. 2001). In this study, we constructed a myogenic vector expressing pmIGF-1 cDNA driven by pig skeletal $\alpha$-actin gene 5'- and 3'- regulators. Although some studies indicated that skeletal $\alpha$-actin was activated only in differentiated myoblasts (Sk and cardiac muscle cells) (Barton et al. 2002; Gunning et al. 1987; Musaro et al. 2001) and that the transgene is expressed only by differentiated muscle cells, our results showed that pig skeletal $\alpha$-actin could strongly drive EGFP reporter gene expression in mouse $\mathrm{C} 2 \mathrm{C} 12$ cells. One reason might be due to the SV40 enhancer included in the vector. The SV40 enhancer is known to be active in a wide variety of tissues and species. It contains a number of sequence motifs that can be bound by protein factors. The SV40 enhancer might have been responsible for activation of the skeletal $\alpha$-actin promoter in $\mathrm{C} 2 \mathrm{C} 12$ cells. In this paper, skeletal $\alpha$-actin could drive EGFP expression in PEF cells, but not in PK15 cells, because the embryo fibroblast cells (PEF) might contain myofibroblast (Sassoon et al. 1988) and PK15 are pig kidney epithelial cells. In addition, the presence of the constructed vector led to EGFP expression at higher levels than those obtained with pEGFP-N1, which suggested that pig skeletal $\alpha$-actin gene 5'- and 3'- regulators are strong in directing expression of the transgene.

Mouse transgenic studies indicated that human IGF-1 was expressed widely, which resulted in internal organ hyperplasia, such as heart, liver, and other organs, and that Tg mice did not live normally (Mathews et al. 1988). In this report, a transgenic mouse model expressing pmIGF-1 was developed by SB transposon integration. Western blotting analysis identified that pmIGF-1 was specifically expressed in Sk muscle from Tg mice, and other tissues showed no expression of pmIGF-1 except for low-level expression in cardiac muscle. These data suggest that we have 
succeeded in generating a transgenic mouse model to express pmIGF-1 peptide specifically in Sk muscle. $\mathrm{G}_{0} \mathrm{Tg}$ mice lived normally to generate the next generation, which will aid in further study of the regulator mechanism of mIGF-1 in muscle development and transgene stability.

Studies reported high levels of hIGF-1 in gastrocnemius muscles of 6-9-monthold transgenic male mice and showed no correlation between gastrocnemius mass and levels of hmIGF-1 protein in the muscle, which suggested that there was a threshold for mIGF-1 levels above which no further enhancement of muscle growth occurred (Criswell et al. 1998). In this report, the overexpression of mIGF-1 led to significantly increased body weights of $\mathrm{F} 1$ adult mice ( $>8$ weeks old). For young mice $(<8$ weeks old), endogenous mIGF-1 content in Sk muscle was high enough to promote muscle growth and transgenic mIGF-1 had no effect on mice. For adult mice ( $>8$ weeks old), endogenous mIGF-1 content decreased and exogenous mIGF-1 started to have an effect on muscle development. We also found that the effect of mIGF-1 overexpression on mice body weights was gender-specific. It is, perhaps, due to the different physiological mechanisms between male and female mice, such as growth hormone level or IGF-1 receptors level. Therefore, further research should be taken, for example, the expression level of IGF-1 or relative hormone at each development stage for both male and female mice. The mIGF-1 in muscles could combine with the IGF-1 receptors of adjacent cell surfaces through the paracrine system to active tyrosinase, which could regulate the expression of myogenic factors and then activate the proliferation and differentiation of muscle satellite cells and induce fusion of myocytes (Izumiya et al. 2008; Blaauw et al. 2009). Our histologic examination of gastrocnemius from 16-week-old male $\mathrm{Tg}$ mice also showed that pmIGF-1 overexpression in Sk muscle obviously increased the numbers of myofibers. Based on this study, further research should be undertaken on older Tg mice to obtain more information on the effect of local mIGF-1 expression in Sk muscle on muscle development.

Establishing an efficient gene integration method using nonviral vectors is important for creating transgenic mouse models. The total transgenic efficiency was only 2-5\% (Sumiyama et al. 2010) when using the common method of pronuclear microinjection of plasmid DNA into fertilized eggs, because survival of injected embryos and integration of plasmid DNA are not efficient. To overcome these problems, novel transgenesis methods based on transposons have been developed in recent years. The foreign DNA was transposed from the plasmid to the genome and transmitted to the next generation very efficiently, with overall transgenic efficiency reaching $>20 \%$ (Sumiyama et al. 2010). In this paper, we obtained a 30\% positive rate of transgenic founder mice by coinjection of the SB transposon vector together with transposase DNA into the pronucleus of fertilized eggs. Three transgenic lines were established by mating three male founder Tg mice with $\mathrm{Wt} \mathrm{C57BL/J6.} \mathrm{The} \mathrm{three} \mathrm{male} \mathrm{founders}$ were all germ-line transgene mice, and the positive rate of $\mathrm{F} 1$ was about $90 \%$. In conclusion, the SB transposon system is a simple and highly efficient transgenesis tool in mice. The high percentage of positive transgenic animals in F1 generation may be due to multi-site insertion mediated with SB transposon technique. However, that transposon mediates multi-site insert and multi-copy transgenes, which 
may cause high phenotypic variance and, sometimes, adverse genetic effects, is still a problem. It will take time to generate single copy transgene offspring.

In summary, we succeeded in effectively generating a $\mathrm{Tg}$ mice model strongly expressing pmIGF-1 specifically in Sk muscle. The mIGF-1 overexpression had an obvious effect on adult mouse muscle growth, which will provide good material for studying the molecular mechanism of muscle growth and development. Experimental data obtained from transgenic mouse models characterized by muscle-specific overexpression of IGF-1 suggested mIGF-1 as therapeutic agents in human muscular dystrophies (Fiorotto et al. 2003; Musarò et al. 2004; Shavlakadze et al. 2004). Pig as an animal model is better than rodents for human comparison (Smink et al. 2002). In this study, we validated the functions of pmIGF-1 and the skeletal $\alpha$-actin regulator. On this basis, we will generate mIGF-1 transgenic pig models using the SB transposon system and cytoplasmic microinjection to obtain more-concrete data for human clinical use.

\section{Conclusions}

In this study, a myogenic specific expression vector expressing pig mIGF-1 was successfully constructed using the 5'- and 3'-regulatory regions of porcine skeletal $\alpha$-actin gene. Transgenic mice models expressing pig mIGF-1 specially in skeletal muscle were generated by the mediation of SB transposon with high transgene efficiency. Pig mIGF-1 overexpression in skeletal muscle of mice promoted myofibers hypertrophy and muscle production, and increased the average body weight of adult mice. Based on this study, transgenic pigs for pig endogenous IGF1 gene may be generated.

Acknowledgements The authors thank the Major project of National Genetically Modified Organism Breeding (grant no. 2018ZX0801003B), Natural Science Foundation of China (Project Nos. 31671313 and 31572364), and the Priority Academic Program Development of Jiangsu Higher Education Institutions (PAPD) for supporting this study.

\section{Compliance with Ethical Standards}

Conflict of interest The authors declare no conflict of interest.

Ethical Approval Animal care and use was approved by the University of Yangzhou University Animal Care and Use Committee.

Open Access This article is distributed under the terms of the Creative Commons Attribution 4.0 International License (http://creativecommons.org/licenses/by/4.0/), which permits unrestricted use, distribution, and reproduction in any medium, provided you give appropriate credit to the original author(s) and the source, provide a link to the Creative Commons license, and indicate if changes were made. 


\section{References}

Asante EA, Boswell JM, Burt DW, Bulfield G (1994) Tissue specific expression of an alpha-skeletal actin lacz fusion gene during development in transgenic mice. Transgenic Res 3:59-66

Barton ER, Morris L, Musaro A et al (2002) Muscle-specific expression of insulin-like growth factor I counters muscle decline in mdx mice. J Cell Biol 157:137-147. https://doi.org/10.1083/jcb.20010 8071

Bell GI, Stempien MM, Fong NM, Rall LB (1986) Sequences of liver cDNAs encoding two different mouse insulin-like growth factor I precursors. Nucl Acids Res 14:7873-7882. https://doi. org/10.1093/nar/14.20.7873

Blaauw B, Canato M, Agatea L et al (2009) Inducible activation of Akt increases skeletal muscle mass and force without satellite cell activation. Faseb 23:3896-3905. https://doi.org/10.1096/fj.09-13187 0

Brennan KJ, Hardeman EC (1993) Quantitative analysis of the human alpha-skeletal actin gene in transgenic mice. J Biol Chem 268:719-725

Carlson DF, Garbe JR, Tan W et al (2011a) Strategies for selection marker-free swine transgenesis using the Sleeping Beauty transposon system. Transgenic Res 20:1125-1137. https://doi.org/10.1007/ s11248-010-9481-7

Carlson DF, Geurts AM, Garbe JR et al (2011b) Efficient mammalian germline transgenesis by cisenhanced Sleeping Beauty transposition. Transgenic Res 20:29-45. https://doi.org/10.1007/s1124 8-010-9386-5

Coleman ME, Demayo F, Yin Kuo Chang et al (1995) Myogenic vector expression of insulin-like growth factor I stimulates muscle cell differentiation and myofiber hypertrophy in transgenic mice. J Biol Chem 270:12109-12116. https://doi.org/10.1074/jbc.270.20.12109

Criswell DS, Booth FW, DeMayo F et al (1998) Overexpression of IGF-I in skeletal muscle of transgenic mice does not prevent unloading-induced atrophy. Am J Physiol 275:E373-E379. https://doi. org/10.1097/00005768-199705001-00384

Fiorotto ML, Schwartz RJ, Delaughter MC (2003) Persistent IGF-I overexpression in skeletal muscle transiently enhances DNA accretion and growth. FASEB J 17:59-60. https://doi.org/10.1096/fj.02

Fischer SE, Wienholds E, Plasterk RH (2001) Regulated transposition of a fish transposon in the mouse germ line. Proc Natl Acad Sci U S A 98:6759-6764. https://doi.org/10.1073/pnas.121569298

Geurts AM, Yang Y, Clark KJ et al (2003) Gene transfer into genomes of human cells by the Sleeping Beauty transposon system. Mol Ther 8:108-117. https://doi.org/10.1016/S1525-0016(03)00099-6

Gunning P, Hardeman E, Wade R et al (1987) Differential patterns of transcript accumulation during human myogenesis. Mol Cell Biol 7:4100-4114. https://doi.org/10.1128/MCB.7.11.4100.Updated

Horie K, Kuroiwa A, Ikawa M et al (2001) Efficient chromosomal transposition of a Tc1/marinerlike transposon Sleeping Beauty in mice. Proc Natl Acad Sci U S A 98:9191-9196. https://doi. org/10.1073/pnas.161071798

Ivics Z, Kaufman CD, Zayed H et al (2004) The Sleeping Beauty transposable element: evolution, regulation and genetic applications. Curr. Issues Mol. Biol. 6:43-56

Ivics Z, Garrels W, Mátés L et al (2014) Germline transgenesis in pigs by cytoplasmic microinjection of Sleeping Beauty transposons. Nat Protoc 9:810-827. https://doi.org/10.1038/nprot.2014.010

Izumiya Y, Hopkins T, Morris C et al (2008) Fast/glycolytic muscle fiber growth reduces fat mass and improves metabolic parameters in obese mice. Cell Metab 7:159-172. https://doi.org/10.1016/j. cmet.2007.11.003

Lund PK, Hoyt EC, Van Wyk JJ (1989) The size heterogeneity of rat insulin-like growth factor-I mRNAs is due primarily to differences in the length of 3'-untranslated sequence. Mol Endocrinol 3:20542061. https://doi.org/10.1210/mend-3-12-2054

Luo G, Ivics Z, Izsvák Z, Bradley A (1998) Chromosomal transposition of a Tc1/mariner-like element in mouse embryonic stem cells. Proc Natl Acad Sci U S A 95:10769-10773. https://doi.org/10.1073/ pnas.95.18.10769

Mátés L (2011) Rodent transgenesis mediated by a novel hyperactive Sleeping Beauty transposon system. Methods Mol Biol 738:87-99. https://doi.org/10.1007/978-1-61779-099-7_6

Mathews LS, Hammer RE, Behringer RR et al (1988) Growth enhancement of transgenic mice expressing human insulin-like growth factor I. Endocrinology 123:2827-2833. https://doi.org/10.1210/ endo-123-6-2827 
Musaro A, McCullagh K, Paul A et al (2001) Localized Igf-1 transgene expression sustains hypertrophy and regeneration in senescent skeletal muscle. Nat Genet 27:195-200. https://doi.org/10.1038/84839

Musarò A, Giacinti C, Borsellino G et al (2004) Stem cell-mediated muscle regeneration is enhanced by local isoform of insulin-like growth factor 1. Proc Natl Acad Sci U S A 101:1206-1210. https://doi. org/10.1073/pnas.0303792101

Rosenthal N, Kornhausert JM, Donoghue M et al (1989) Myosin light chain enhancer activates musclespecific, developmentally regulated gene expression in transgenic mice. Biochemistry 86:7780-7784

Sassoon DA, Garner I, Buckingham M (1988) Transcripts of alpha-cardiac and alpha-skeletal actins are early markers for myogenesis in the mouse embryo. Development 104:155-164

Schefe JH, Lehmann KE, Buschmann IR et al (2006) Quantitative real-time RT-PCR data analysis: current concepts and the novel "gene expression's CT difference" formula. J Mol Med (Berl) 84:901910. https://doi.org/10.1007/s00109-006-0097-6

Shavlakadze T, White J, Hoh JFY et al (2004) Targeted expression of insulin-like growth factor-I reduces early myofiber necrosis in dystrophic mdx mice. Mol Ther 10:829-843. https://doi.org/10.1016/j. ymthe.2004.07.026

Shavlakadze T, Winn N, Rosenthal N, Grounds MD (2005) Reconciling data from transgenic mice that overexpress IGF-I specifically in skeletal muscle. Growth Horm. IGF Res. 15:4-18

Smink JJ, Koedam JA, Koster JG, van Buul-Offers SC (2002) Dexamethasone-induced growth inhibition of porcine growth plate chondrocytes is accompanied by changes in levels of IGF axis components. J Endocrinol 174:343-352. https://doi.org/10.1677/joe.0.1740343

Sumiyama K, Kawakami K, Yagita K (2010) A simple and highly efficient transgenesis method in mice with the Tol2 transposon system and cytoplasmic microinjection. Genomics 95:306-311. https:// doi.org/10.1016/j.ygeno.2010.02.006

Tesson L, Cozzi J, Ménoret S et al (2005) Transgenic modifications of the rat genome. Transgenic Res 14:531-546

Tonkin J, Temmerman L, Sampson RD et al (2015) Monocyte/macrophage-derived IGF-1 orchestrates murine skeletal muscle regeneration and modulates autocrine polarization. Mol Ther 23:1189-1200. https://doi.org/10.1038/mt.2015.66

Tschida BR, Largaespada DA, Keng VW (2014) Mouse models of cancer: Sleeping Beauty transposons for insertional mutagenesis screens and reverse genetic studies. Semin Cell Dev Biol 27:86-95

Yang H, Adamo ML, Koval AP et al (1995) Alternative leader sequences in insulin-like growth factor I mRNAs modulate translational efficiency and encode multiple signal peptides. Mol Endocrinol 9:1380-1395. https://doi.org/10.1210/mend.9.10.8544846

Yant SR, Meuse L, Chiu W et al (2000) Somatic integration and long-term transgene expression in normal and haemophilic mice using a DNA transposon system. Nat Genet 25:35-41. https://doi. org/10.1038/75568

Zanta MA, Belguise-Valladier P, Behr JP (1999) Gene delivery: a single nuclear localization signal peptide is sufficient to carry DNA to the cell nucleus. Proc Natl Acad Sci U S A 96:91-96. https://doi. org/10.1073/pnas.96.1.91 